\title{
TRAJETO DE MENOR CUSTO AMBIENTAL NO TRECHO LESTE DO RODOANEL METROPOLITANO DE SÃO PAULO
}

\author{
Environmental least cost path in the eastern portion of \\ Metropolitan Ring Road of São Paulo \\ Camino de menor costo ambiental en el tramo este de la \\ carretera de circunvalación metropolitana de São Paulo
}

\section{Carlos Roberto Libonati Machado}

Mestre em Geografia Física pela Universidade de São Paulo. Professor dos cursos de Geografia e de Engenharia Civil da Unicastelo. Rua Carolina Fonseca, 584, CEP 08230-030, São Paulo (SP), Brasil. E.mail: carlos.libonati@uol.com.br

\section{Alfredo Pereira Queiroz Filho}

Professor do Departamento de Geografia, Faculdade de Filosofia, Letras e Ciências Humanas da Universidade de São Paulo. Av. Prof. Lineu Prestes, 338, CEP 05508-080, São Paulo (SP), Brasil. E.mail: aqueiroz@usp.br

\begin{abstract}
Resumo
O trabalho analisa o trajeto de menor custo (TMC) ambiental no trecho leste do Rodoanel Metropolitano de São Paulo. O algoritmo de TMC foi aplicado sobre os mapas temáticos (superfícies de custo) gerados pelas metodologias de fragilidade ambiental (ROSS, 1994) e vulnerabilidade à erosão (CREPANI, et al, 2001) e os resultados foram comparados ao traçado final da rodovia. Constatou-se que a intersecção entre os TMC e o trajeto construído foi baixa: $21,2 \%$ na carta de vulnerabilidade e $4,3 \%$ na carta de fragilidade. Os TMCs também apresentaram uma sobreposição pouco relevante entre eles (6\%). Assim, considera-se que as variáveis ambientais deste estudo de caso se mostraram relevantes para a etapa inicial do projeto do empreendimento. $\mathrm{O}$ aumento da intersecção entre os TMCs e o traçado construído tende a ocorrer com o refinamento das superfícies de custo ambiental, com a incorporação de dados sobre a geometria do traçado, métodos e custos construtivos, procedimentos e custos operacionais.
\end{abstract}

Palavras chave: Trajeto de menor custo, Fragilidade, Vulnerabilidade, Rodoanel.

\begin{abstract}
The paper analyzes the environmental least cost path (LCP) in the eastern portion of the Metropolitan Ring Road of São Paulo. The LCP algorithm was applied on thematic maps (cost surface), generated by the methodologies of environmental fragility (Ross, 1994) and vulnerability to erosion (CREPANI, et al, 2001) and the results were compared to the final route of the highway. It was found that the intersection between the LCP and the constructed path was low: $21.2 \%$ in the vulnerability's map and $4.3 \%$ in the fragility's map. The LCP also showed an overlap of little relevance between them (6\%).
\end{abstract}


Thus, it is considered that the environmental variables in this case study were relevant for the initial stage of the project design. The increasing intersection between LCPs and route built tends to occur with the refinement of surfaces environmental cost, with the incorporation of data on the geometry of the layout, construction methods and costs, procedures and operating costs.

Key words: Least cost path, Fragility, Vulnerability, Ring Road.

\section{Resumen}

El trabajo analiza el camino de menor costo ambiental (CMC) en el tramo este de la Carretera de Circunvalación Metropolitana de São Paulo. El algoritmo CMC se aplicó a los mapas temáticos (superficie de costo), generados por las metodologías de fragilidad ambiental (Ross, 1994) y la vulnerabilidad a la erosión (CREPANI, et al, 2001) y los resultados se compararon con la ruta final de la carretera. Se constató que la intersección entre el CMC y el camino construido fue baja: $21,2 \%$ en el mapa de la vulnerabilidad y 4,3\% en el mapa de la fragilidad. Los CMCs también mostraron una superposición de poca relevancia entre ellos (6\%). Así, se considera que las variables ambientales en este estudio de caso eran relevantes para la etapa inicial del diseño del proyecto. El aumento de intersección entre los CMCs y ruta construida tiende a ocurrir con el refinamiento de superficies de costo ambiental, con la incorporación de datos sobre la geometría del diseño, métodos de construcción y los costos, los procedimientos y los costos de operación.

Palabras clave: Camino de menor costo, Fragilidad, Vulnerabilidad, Carretera de Circunvalación. 


\section{INTRODUÇÃO}

O uso do algoritmo de trajeto de menor custo (TMC) para analisar problemas complexos se tornou possível com a ampliação da capacidade de processamento dos computadores. Atualmente, essa função está disponível em inúmeros programas, como os denominados Sistemas de Informações Geográficas (LEE, STUCKY, 1998).

Sua aplicação é variada. Dentre os exemplos mais relevantes, destacam-se a seleção da rota mais econômica para transportar mercadorias, baseada em dados topográficos e de uso do solo (NOVALINE JAGA et al., 1993), a escolha do melhor traçado para oleodutos, sobre dados de uso do solo (FELDMAN et al., 1996), planejamento de pontes e túneis para rodovias (YU et al., 2003), avaliação multicritério para o traçado de rodovias no Ártico (ATKINSON et al., 2005) e definição de traçado de linhas de transmissão, para reduzir os impactos ambientais (BAGLI et al., 2011).

É nesse contexto ambiental que o trabalho se insere. Seu objetivo é analisar o trajeto de menor custo (TMC) ambiental no trecho leste do Rodoanel Metropolitano de São Paulo. O algoritmo de TMC foi aplicado sobre os mapas temáticos gerados pelas metodologias de fragilidade ambiental (ROSS, 1994) e vulnerabilidade à erosão (CREPANI, et al, 2001) e os resultados foram comparados ao traçado final da rodovia.

\section{Rodoanel Metropolitano}

Segundo DERSA (2008), o Rodoanel Metropolitano de São Paulo foi concebido para interligar o sistema rodoviário da Grande São Paulo (ver Figura 1). Os trechos oeste e sul já estão em atividade. A construção do trecho norte começou em 2013 e deve ser concluída no primeiro semestre de 2016.

O trecho leste encontra-se em fase final de obras e a previsão para o início das operações é o primeiro semestre de 2014. Seus principais objetivos são: a) ordenar o tráfego de transposição da RMSP, principalmente o de caminhões, desviando-o do centro da Região Metropolitana, reduzindo os tempos de percurso entre rodovias e a solicitação dos sistemas viários locais, e b) hierarquizar e estruturar o transporte de passageiros e cargas na RMSP, servindo de alternativa para os fluxos de longa distância entre as sub-regiões da metrópole; promovendo a ligação entre os municípios da Região Metropolitana. 
De acordo com DERSA (2008), as principais diretrizes adotadas nas etapas de projeto e construção foram:

- evitar áreas com declividade acentuada e solo inadequado ao suporte do leito rodoviário, e áreas densamente ocupadas, para que não haja ruptura do tecido urbano e elevados gastos com as desapropriações;

- minimizar a interferência em parques, áreas de proteção ambiental, áreas de proteção aos mananciais e sistemas de drenagem natural;

- estar inserido em uma faixa entre 20 e $40 \mathrm{~km}$ do centro de São Paulo. A área inferior a $20 \mathrm{~km}$ corresponde à área urbana densamente ocupada e, a superior a $40 \mathrm{~km}$, apresenta baixa relação custo/benefício aos deslocamentos;

- promover a organização do espaço urbano pela integração de diretrizes metropolitanas às municipais, induzindo a expansão urbana a oeste e a leste da capital e inibindo a ocupação ao sul e ao norte.

\section{Figura 1 - Localização do Rodoanel Metropolitano de São Paulo}

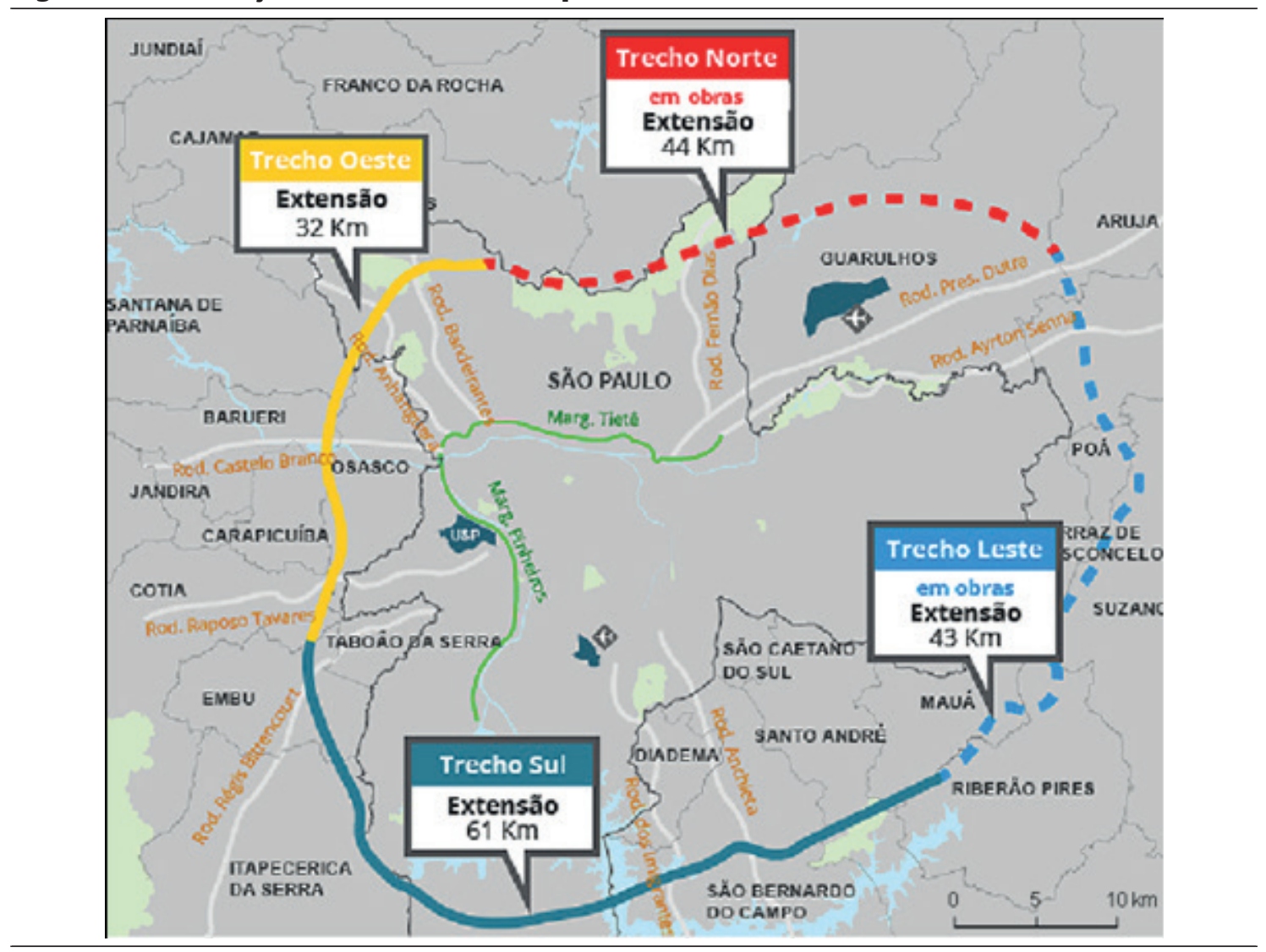

Fonte: Adaptado de DERSA (2008) 
O trecho leste do rodoanel possui 43,5 km e ocupa uma área de $6,45 \mathrm{~km}^{2}$ (largura média de 148 m). Interliga as rodovias Presidente Dutra (BR-116) e Ayrton Senna (SP-070) ao Trecho Sul do Rodoanel, que termina no município de Mauá, logo após cruzar as rodovias Anchieta e dos Imigrantes. Seu traçado passa por seis municípios: Ribeirão Pires, Mauá, Suzano, Poá, Itaquaquecetuba e Arujá (Figura 2).

Este trecho faz a ligação entre o Porto de Santos e o Aeroporto Internacional de Guarulhos. Facilita a integração de importantes áreas industriais da Região Metropolitana de São Paulo, como o ABC, a Zona Leste da cidade e a região do Alto Tietê, e modifica as estruturas urbanas periféricas e suas respectivas funções econômicas tradicionais como, por exemplo, o cultivo de produtos hortifrutigranjeiros.

A região do trecho leste está inserida no Planalto Paulistano e se caracteriza por relevos de colinas e morrotes, com aproximadamente 800 metros de altitude, e de morros (900 m). É composto por micaxistos, filitos, migmatitos, anfibolitos, granitos, gnaisses. Apresentam sedimentos terciários da Formação São Paulo e unidades correlatas, nas formas de relevo mais suaves, e depósitos quaternários nas planícies aluviais.

Embora esteja numa área de transição, o clima é considerado do tipo Temperado Úmido, com inverno seco. As baixas precipitações neste período não ultrapassam $50 \mathrm{~mm}$. As precipitações estão concentradas entre dezembro e fevereiro, com médias acima de 200 $\mathrm{mm}$, caracterizando verões quentes e úmidos (Tarifa e Azevedo, 2001).

Os solos predominantes são: Argissolos Vermelho-Amarelo distróficos, textura argilosa e média/argilosa que se associam a Cambissolos Háplicos, distróficos, textura argilosa que ocorrem associados aos relevos de morros e de morrotes. A presença de textura binária e declives acentuados tornam esses solos muito vulneráveis à erosão, que é agravada pela presença de afloramentos rochosos, que restringem o tráfego (Oliveira, 1999). 


\section{RODOANEL LESTE CARTA IMAGEM}

- Rodoanel Leste

FONTE:

Imagem LANDSAT 5 - TM 219076 Data de Passagem: 24/10/2009
Composiçlo Colorida SR 4G 38
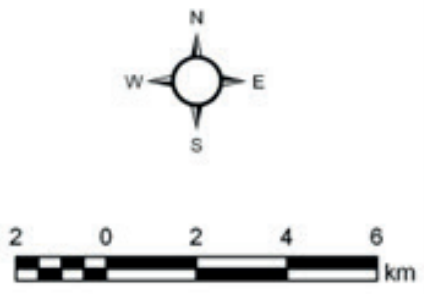

Propecto Univernal Transwersa de Mercator Ditum Verticat imbitubs $.5 \mathrm{C}$

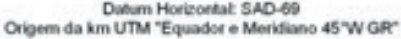

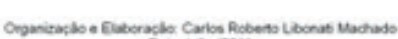
Dot intorit

$0 \times$

ơ

Uิ

릉ำ

₹

$0 \sum^{n}$

రำ

$\frac{0}{\frac{1}{4}}$

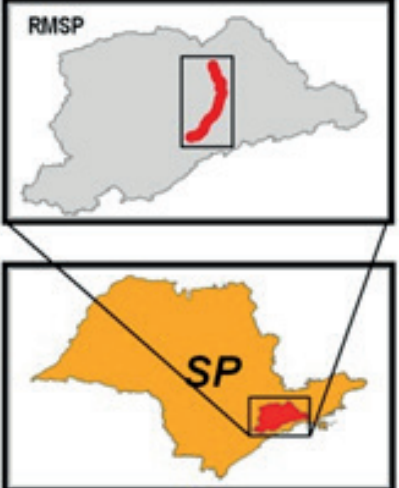

Mapa de Localização

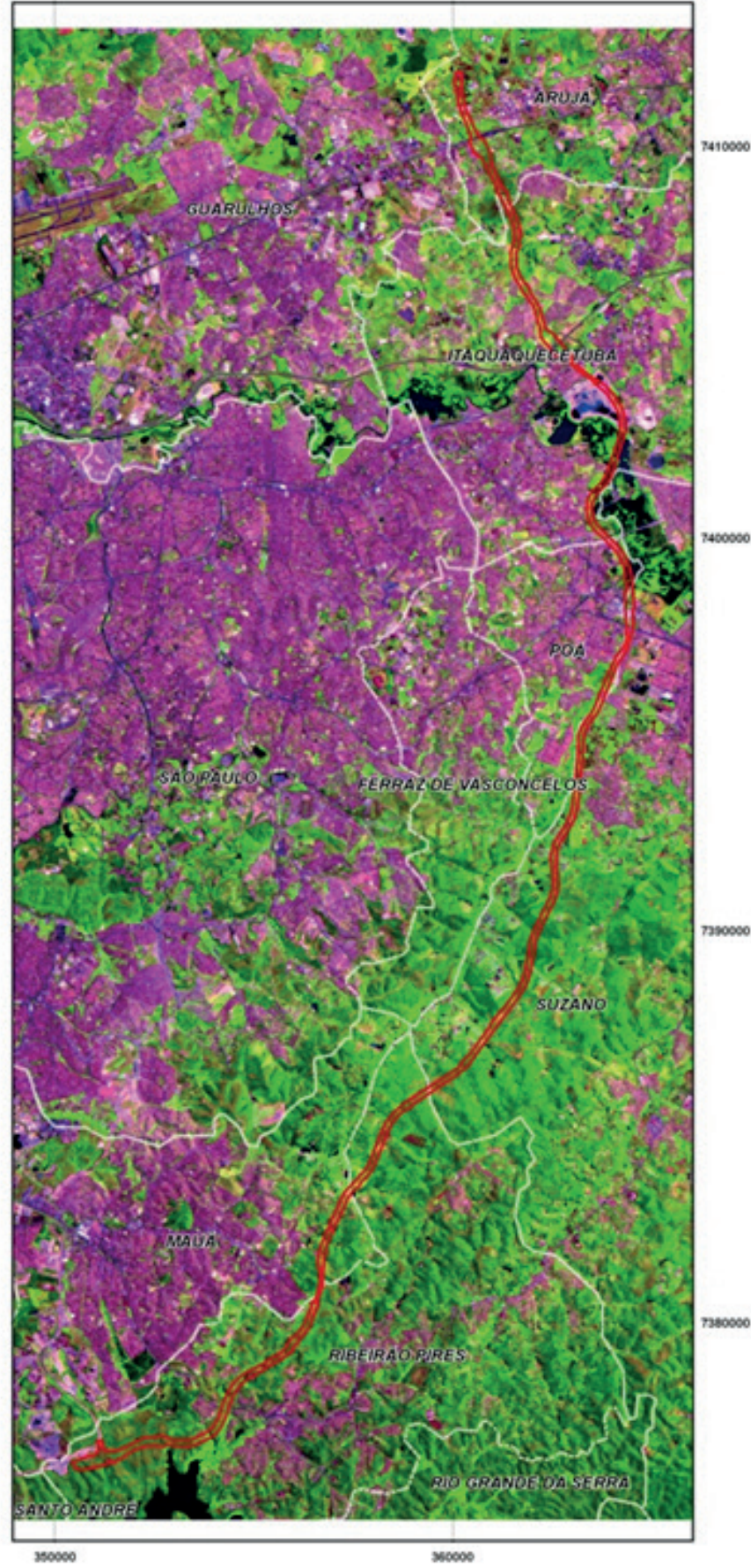

a

a 
O trecho leste do rodoanel cruza inúmeras bacias hidrográficas. Na parte sul, as bacias são tributárias da Represa Billings e do Rio Tamanduateí. Em direção ao norte, o rodoanel atravessa a bacia do Rio Guaió e do Córrego Itaim, afluentes da margem esquerda do Rio Tietê. Na parte central, corta a Planície Fluvial do Rio Tietê. Na porção norte, cruza as bacias do Ribeirão Caputera, Córrego Água Branca e Rio Baquirivu-Guaçu.

Esse trecho do rodoanel se localiza no limite leste da mancha urbana da Região Metropolitana de São Paulo (RMSP). Está inserido no domínio da Mata Atlântica, cuja cobertura vegetal original era constituída de formações da Floresta Ombrófila Densa Montana e ecossistemas associados. A cobertura vegetal atual é composta por formações campestres e florestais, remanescentes da Floresta Ombrófila Densa com diferentes graus de perturbação antrópica, além de reflorestamentos comerciais e de formações mistas (IBGE, 2005).

\section{METODOLOGIA}

\section{Fragilidade Ambiental}

A metodologia de fragilidade ambiental foi desenvolvida por ROSS (1994). Baseia-se na integração de cinco cartas temáticas: geomorfologia (índice de dissecação do relevo), solos, cobertura vegetal/uso da terra e clima (regime pluviométrico).

O autor propõe a geração de uma carta-síntese que representa a fragilidade do terreno em cinco categorias hierárquicas: 1. Muito Fraca; 2. Fraca; 3. Média; 4. Forte; 5. Muito Forte. Nela, a área estudada é classificada em Unidades Ecodinâmicas Estáveis e Instáveis, com diferentes graus (muito fraca a muito forte) de Instabilidade Potencial e Emergente.

A classificação é expressa pela combinação de quatro números, que variam entre 1 (valor mais baixo) e 5 (valor mais alto). O primeiro dígito representa o grau de declividade; o segundo, a susceptibilidade à erosão dos tipos de solos; o terceiro, o grau de proteção aos solos pela cobertura vegetal e uso da terra; o quarto indica a pluviosidade. Exemplos: áreas com valores do tipo 1111, menos frágeis, até o valor extremo 5555, na qual todas as variáveis são desfavoráveis, isto é: declividade muito alta, solos muito frágeis aos processos erosivos, desprovida de cobertura vegetal, distribuição irregular de chuva e volumes superiores a $2500 \mathrm{~mm}$ por ano.

O índice de dissecação do relevo foi elaborado de acordo com a matriz proposta por Ross (1992). Está baseada na relação de densidade de drenagem e dimensão interfluvial 
média para a dissecação, no plano horizontal, e nos graus de entalhamento dos canais de drenagem para a dissecação, no plano vertical.

A base cartográfica foi vetorizada a partir de arquivos matriciais, no formato tif, das cartas topográficas do IBGE, escala 1:50.000, de 1984, folhas de Itaquaquecetuba, SF-23-Y-D-I-3 e Mauá, SF-23-Y-D-IV-1. A carta de fragilidade ambiental do entorno do trecho leste do rodoanel pode ser observada na figura 3.

O mapa de solos foi extraído do Mapa Pedológico do Estado de São Paulo, escala 1:500.000, de 1999, do Instituto Agronômico de Campinas. Os dados de chuva foram obtidos de quatro postos pluviométricos, entre 1984 e 2004, distribuídos pela área de estudo. Foram adotados os níveis hierárquicos climatológicos propostos por Spörl (2001). Esses parâmetros analisam as características climatológicas de acordo com a intensidade do efeito pluviométrico sobre os processos morfodinâmicos.

A carta de uso da terra e de cobertura vegetal foi gerada pelo processamento e interpretação das imagens de satélite e aferida pelos trabalhos de campo. A imagem utilizada foi do satélite LANDSAT TM 5, 291/076, bandas 1, 2, 3, 4, 5 e 7, de 24/10/2009. A classificação supervisionada foi realizada com o algoritmo MAXVER. A matriz de erro mostrou exatidão global de 83\% e índice Kappa de 0,78, para as classes: mata, capoeira/pastagem, corpos de água, área urbana consolidada, área urbana em expansão, solo exposto/mineração. As tipologias de cobertura vegetal e uso da terra e seus respectivos graus de proteção foram identificadas de acordo com a proposta de Kawakubo (2005). 


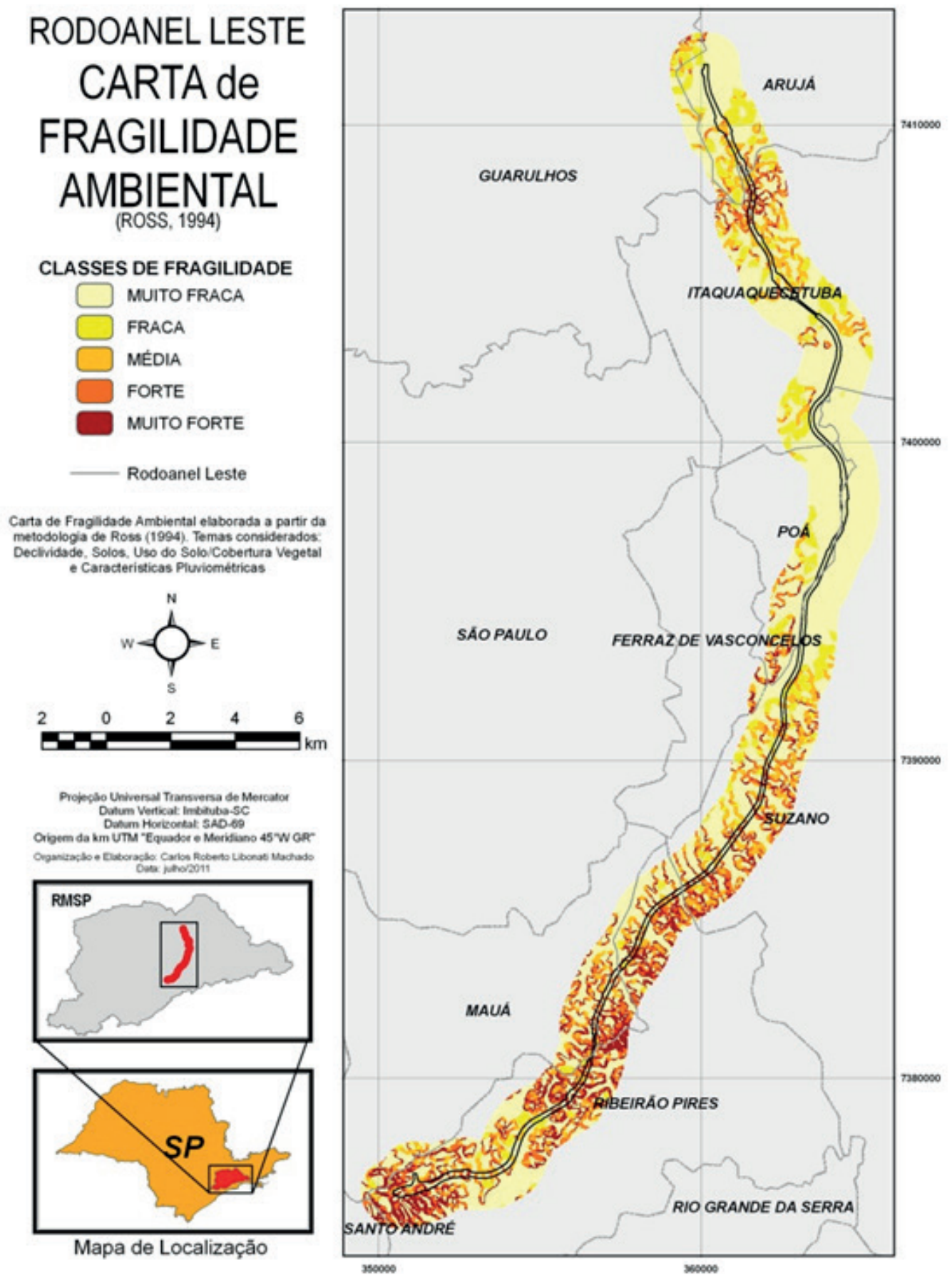

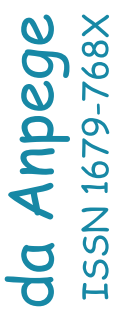




\section{Vulnerabilidade à Erosão}

A metodologia proposta por Crepani et al. (2001) possibilita a elaboração de cartas de vulnerabilidade à erosão. Está baseada no conceito de ecodinâmica de Tricart (1977) e foi concebida para subsidiar o zoneamento ecológico-econômico da Amazônia.

Fundamenta-se na relação entre morfogênese (processo de formação do relevo) e pedogênese (processo de formação do solo) e na utilização sistemática de imagens LANDSAT. Visa a delimitação de unidades homogêneas de paisagens (UTBs), traçadas após a análise integrada dos temas: Geologia, Geomorfologia, Pedologia, Vegetação e Clima. A carta de vulnerabilidade a erosão pode ser visualizada pela figura 4.

As etapas para a geração das cartas de vulnerabilidade ambiental, de acordo com Crepani et al. (2001), são:

- elaboração de um mapa de unidades homogêneas de paisagens (UTBs), a partir da análise e interpretação de composições coloridas formadas com as bandas 3 , 4 e 5 do sensor TM. São considerados os padrões identificados pelas variações de cor, textura, forma, padrão de drenagem e relevo;

- associação das informações temáticas existentes ou extraídas da própria interpretação das imagens (Geologia, Geomorfologia, Solos, Cobertura Vegetal / Uso da Terra e Clima) com o mapa das unidades homogêneas, denominadas unidades territoriais básicas (UTBs);

- classificação do grau de estabilidade ou vulnerabilidade de cada unidade ambiental conforme sua relação com os processos de morfogênese e pedogênese. A vulnerabilidade é expressa pela atribuição de valores (de 1,0 a 3,0), formando um gradiente de 21 classes de vulnerabilidade à perda de solo. Elas expressam as situações em que há o predomínio dos processos de pedogênese, às quais se atribuem valores próximos de 1,0; passando por situações intermediárias (valores ao redor de 2,0) e situações de predomínio dos processos de morfogênese (valores próximos de 3,0);

- a vulnerabilidade é definida pela média dos valores atribuídos a cada tema para esta UTB, segundo a equação abaixo (1), que busca representar a posição desta unidade dentro da escala de vulnerabilidade natural à perda de solo. 
Onde:

G: vulnerabilidade da geologia;

R: vulnerabilidade da geomorfologia;

S: vulnerabilidade dos solos;

Vg: vulnerabilidade da vegetação/uso da terra;

C: vulnerabilidade do clima

Os mapas de solos, vegetação e clima foram os mesmos citados no item anterior. O mapa geológico foi extraído da Carta Geológica da Região Metropolitana de São Paulo, escala 1:100.000, de 1980, da EMPLASA.

Figura 4 - Carta de vulnerabilidade à erosão do trecho leste do rodoanel

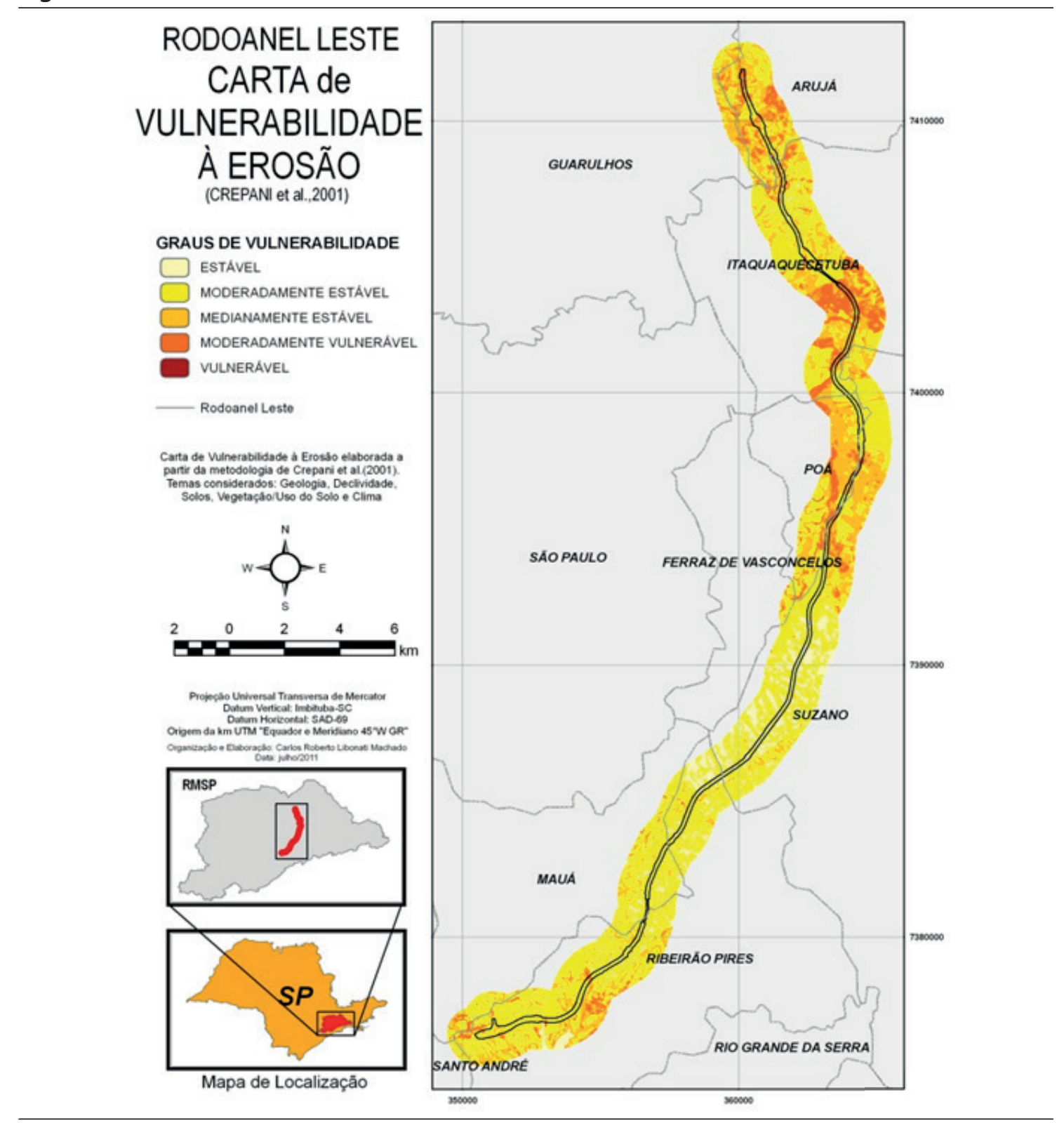




\section{Trajeto de Menor Custo (TMC)}

De acordo com Adriaensen et al (2003), o modelo de TMC utiliza um algoritmo que determina um caminho entre dois pontos, numa superfície matricial, com base em um custo teórico mínimo cumulativo.

O trajeto de menor custo permite que os pesquisadores encontrem o caminho "mais adequado" para conectar dois locais em uma superfície de custo (BAGLI et al, 2011). A superfície de custo (ou fricção) é um mapa estruturado matricialmente cujas células expressam valores que representam o "esforço" para percorrê-las. Embora tenha esse nome, o custo não representa somente aspectos econômicos. Neste trabalho, por exemplo, cada célula da matriz está associada a um valor que indica o potencial de fragilidade e de vulnerabilidade ambiental na área de influência direta do trecho leste do rodoanel.

O TMC foi executado com o software ArcGIS, extensão Spatial Analyst. Os dois novos traçados foram elaborados com a função Least-cost Path Analysis. O primeiro percorreu a carta de fragilidade ambiental (ROSS, 1994) e, o segundo, a carta de vulnerabilidade à erosão (CREPANI et al., 2001). As principais etapas foram:

- definição dos Vértices de Origem e de Destino: estabelecer os pontos onde se começam e terminam os traçados automáticos;

- seleção da superfície de custo: escolher o mapa que representa o esforço de deslocamento.

A função Least-cost Path Analysis cria uma linha sobre o mapa temático, ao percorrer as células que tem o menor custo acumulado. Este processo é repetido até a origem e o destino se unirem. O caminho traçado representa a soma mais baixa de valores de células entre os dois pontos.

Nesse estudo de caso, o vértice de origem se localiza no final do Trecho Sul do Rodoanel, entre os municípios de Mauá e Ribeirão Pires. O vértice de destino coincide com a futura ligação entre os Trechos Norte e Leste do Rodoanel, onde termina o trecho leste. As cartas de fragilidade ambiental (Figura 3), e de vulnerabilidade à erosão (Figura 4), foram usadas como superfícies de custo. Na primeira carta, as áreas de fragilidade muito forte representam o maior custo e, as de fragilidade muito fraca, o menor. Da mesma forma, na segunda carta, a classe vulnerável representa o maior custo e, a estável, o menor custo ao deslocamento. 


\section{RESULTADOS}

Os trajetos de menor custo (TMC) ambiental, sobre a carta de fragilidade e de vulnerabilidade, e o traçado oficial do trecho leste do Rodoanel Metropolitano de São Paulo estão representados na figura 5 e expressos numericamente na tabela 1.

A tabela 1 representa a área total, a intersecção dos trajetos (comprimento e percentual) e a intersecção entre as metodologias de fragilidade e de vulnerabilidade.

Tabela 1: Comparação quantitativa e percentual entre os Trajetos do Rodoanel

\begin{tabular}{|c|c|c|c|}
\hline TRAJETOS & FAIXA de DOMÍNIO & INTERSECÇÃO DERSA & \multirow{4}{*}{$\begin{array}{c}\text { INTERSECÇÃO } \\
\text { ROSS - } \\
\text { CREPANI } \\
0,42 \mathrm{~km}^{2}(6 \%)\end{array}$} \\
\hline DERSA & $6,45 \mathrm{~km}^{2}$ & $6,45 \mathrm{~km}^{2}(100 \%)$ & \\
\hline ROSS & $6,98 \mathrm{~km}^{2}$ & $0,28 \mathrm{~km}^{2}(4,3 \%)$ & \\
\hline CREPANI & $7,05 \mathrm{~km}^{2}$ & $1,37 \mathrm{~km}^{2}(21,2 \%)$ & \\
\hline
\end{tabular}

Ao observar a figura 5 e a tabela 1, constata-se que:

- o percentual de intersecção entre os TMCs e o traçado oficial do rodoanel é muito baixo;

- dentre os traçados de menor custo avaliados, o gerado sobre a carta de vulnerabilidade (Crepani et al, 2001) mostrou uma intersecção um pouco mais elevada $\left(1,37 \mathrm{~km}^{2}\right.$ ou $\left.21,2 \%\right)$ do que a de fragilidade (ROSS, 1994), cujo resultado foi $0,28 \mathrm{~km}^{2}$ de intersecção ou $4,3 \%$;

- a intersecção entre os TMCs ambientais foi baixa. Os trajetos se sobrepuseram apenas $0,42 \mathrm{~km}^{2}(6 \%)$ nas cartas de fragilidade e vulnerabilidade. 


\section{RODOANEL LESTE COMPARAÇÃO DOS TRAJETOS}

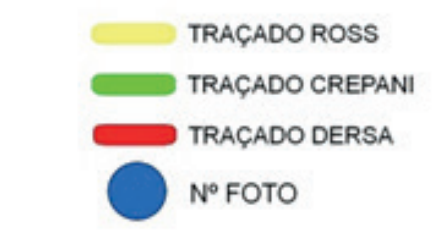

Carta dos Trajetos do Rodoanel etetuados scbre as classes de Fragindade Ambiertal (ROSS, 1904), as classes de Vulnerabilidade a Erosao (CREPAN. et al., 2001). Processo automático executado no
sotwware ArcGis extensto Spatial Analyst.
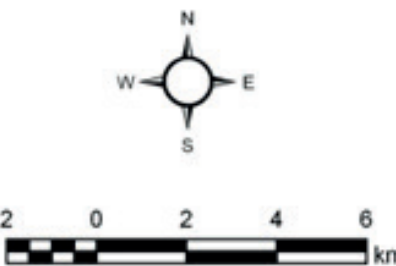

Propplo Univenal Transvena de Morcabo: Disum Verticat imbitita-sc

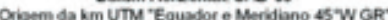

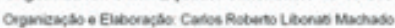

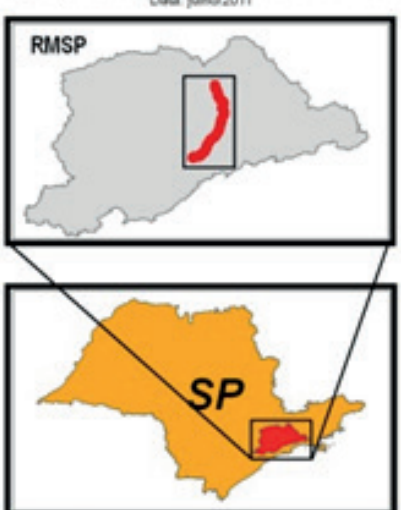

Mapa de Localizaçăo

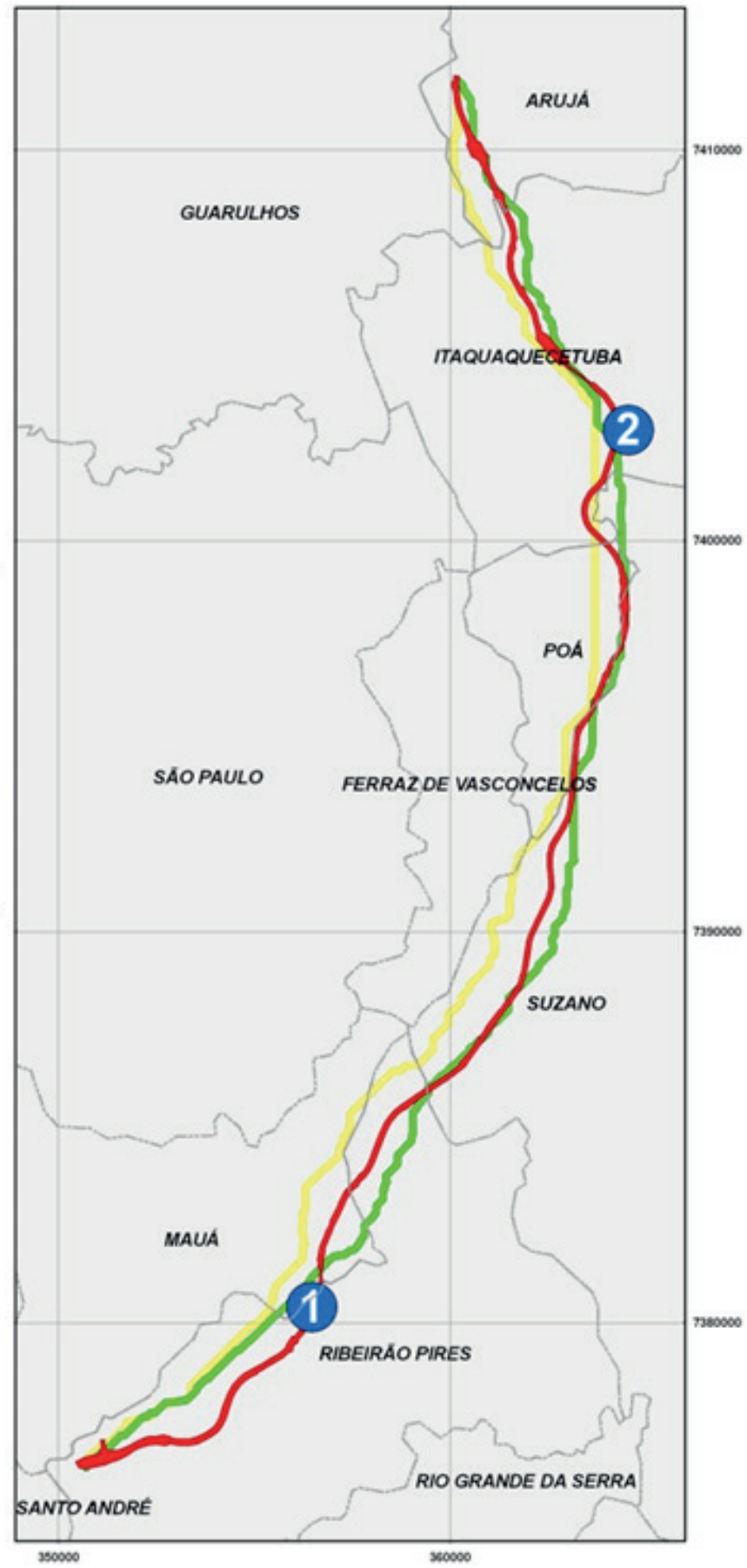

$\frac{0}{4}$ 


\section{DISCUSSÃO}

A análise dos trajetos de menor custo (TMC) ambiental do trecho leste do Rodoanel Metropolitano de São Paulo enfatizou dois aspectos principais: as diferenças entre os trajetos, o oficial e o das metodologias ambientais, e a diferenças entre os TMCs, gerados sobre os mapas de fragilidade e de vulnerabilidade.

\section{Diferenças entre Trajetos}

a intersecção entre o trajeto oficial do rodoanel e os dois TMCs ambientais foi muito baixa. O eixo viário construído se sobrepôs $21,2 \%$ ao TMC gerado pela metodologia de vulnerabilidade à erosão (CREPANI et al, 2001) e apenas 4,3\% ao TMC de fragilidade ambiental (ROSS, 1994).

Acredita-se que essas discrepâncias possam ser justificadas pelas diferenças metodológicas entre as superfícies de custo (fragilidade e vulnerabilidade) e o construído. De acordo com o DERSA (2008), o sistema de análise adotou múltiplos critérios, isto é, usou outras variáveis além das características ambientais, como, por exemplo, os componentes de engenharia rodoviária, os aspectos econômicos e políticos.

Considerando o distinto número e tipos de variáveis, era de se esperar houvesse diferenças entre o traçado construído e os TMCs. O trajeto oficial considerou um conjunto muito maior de elementos, como a geometria do traçado, métodos e custos construtivos, procedimentos e custos operacionais. No entanto, as disparidades foram maiores do que o inicialmente esperado.

Mesmo que as diferenças observadas sejam grandes, percebe-se a relevância dos critérios ambientais, pois o traçado construído buscou: 1) ocupar áreas antropizadas de baixa densidade, não interferindo com atividades econômicas consolidadas (indústrias, centros comerciais e de serviços de grande porte); 2) privilegiar o percurso sobre relevos favoráveis e de menor fragilidade, como colinas, morrotes e morros baixos, não utilizando áreas de planícies aluviais, em que predominam solos inconsolidados; 3 ) evitar os fragmentos florestais significativos e as unidades de conservação.

A integração das variáveis ambientais e construtivas no Trecho Leste do Rodoanel pode ser observada em dois pontos específicos, nos quais as restrições ambientais são consideráveis: passagem próximo ao Parque Municipal da Gruta Santa Luzia (Foto 1) e o trecho na planície aluvial do rio Tietê (Foto 2). 


\section{Foto 1 - Passagem próxima ao Parque Municipal da Gruta Santa Luzia}
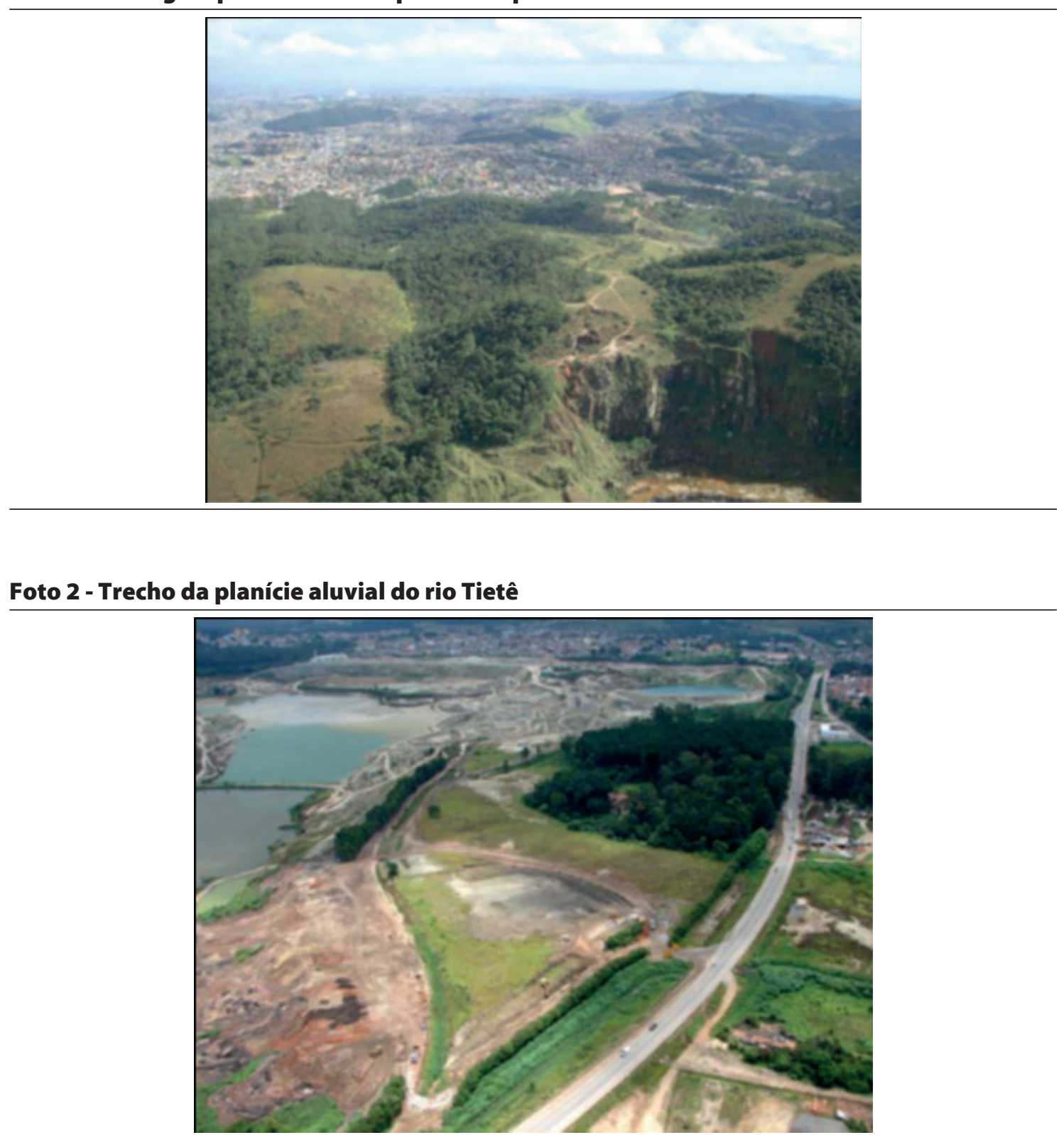

(1)

\section{Foto 2 - Trecho da planície aluvial do rio Tietê}

O Parque Gruta Santa Luzia (Foto 1) é uma Unidade de Conservação municipal. Apresenta amplitudes que variam entre 25 e 85 metros de altitude e declividades acentuadas, entre 15 e $40 \%$. Caracterizam-se por morrotes sustentados por granitos que, em condições naturais, são susceptíveis aos processos erosivos. Podem, contudo, ser induzidos por usos inadequados, principalmente quando ocorre a remoção do solo superficial.

O trecho da foto 2 possui terrenos inconsolidados, pouco favoráveis à implantação da rodovia. São terrenos planos, constituídos por argila e silte, ricos em matéria orgânica, areia fina a grossa e cascalho, que em vários locais estão assoreados, recobertos por aterros

a 
e entulhos. Ocorrem canais aluviais meândricos, em muitos pontos retificados em conseqüência da urbanização e mineração, responsável direta pela formação de lagos.

Nessas áreas, cujas restrições e impactos ambientais foram considerados muito elevados (DERSA, 2008), o rodoanel utilizou a transposição por viadutos, em partes da planície aluvial, e por túneis, ao cruzar morros altos sustentados por granitos.

O túnel possui uma extensão de 920 metros e se localiza sob o limite do parque Santa Luzia, que é um divisor d'água. Os emboques do túnel ocorrem na vertente oposta à ocupada pelo parque, próximo a áreas de mineração do município de Ribeirão Pires. Isso representa menor impacto, pois evita a interferência na vegetação preservada do parque, além de contornar os principais fragmentos de vegetação em estágio avançado e médio de regeneração das proximidades.

Sobre a planície aluvial do rio Tietê, o rodoanel se alinha com o limite oeste da várzea, acompanhando as áreas de ocupação urbana consolidadas do município de Itaquaquecetuba e evitando as áreas ao leste, ocupadas por uma rodovia de interligação dos municípios de Suzano e Poá com a rodovia Ayrton Senna e por uma indústria de papel e celulose. Um pouco antes das cavas de mineração, o traçado oficial do rodoanel intercepta a várzea para atingir a sua outra margem (leste), próximo à intersecção com a rodovia Ayrton Senna.

O TMC gerado sobre a superfície de custo da metodologia ambiental de Crepani et al. (2001), percorre, nestes dois trechos, a região da várzea do rio Tietê. A margem leste da planície aluvial, atualmente ocupada por uma rodovia local, foi evitada pelo traçado oficial do rodoanel. Na região do Parque Santa Luzia, contorna à oeste do maciço granítico, evitando os locais mais inclinados e passa sobre partes da referida Unidade de Conservação, ao contrário do traçado oficializado, que transpõe o maciço através de túnel (Figura 6). 


\section{Figura 6 - Detalhe da comparação dos traçados do rodoanel: oficial e de menores custos}

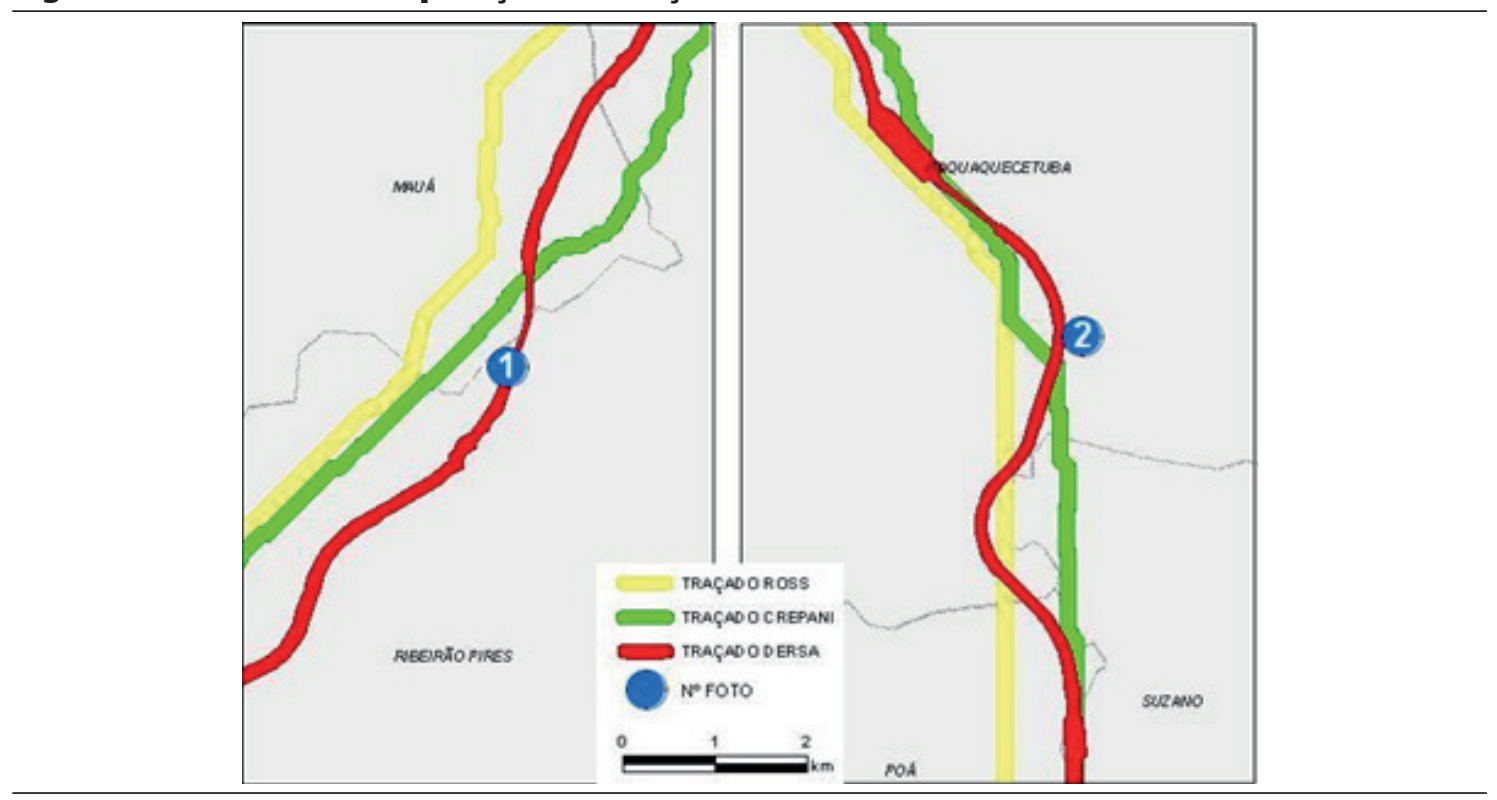

Assim, deve-se reconhecer a importância dos elementos da engenharia rodoviária no traçado oficial do Rodoanel. Não foi possível quantificar, mas acredita-se que características como: a geometria do traçado (rampas e sinuosidades), o tráfego local e o custo de implantação da obra foram quesitos fundamentais na definição final do traçado.

Em decorrência, a suposição é de que, apesar das propostas metodológicas aqui tratadas (fragilidade, vulnerabilidade) servirem como subsídio ao planejamento e gerenciamento do uso e ocupação do solo, permitindo mais agilidade no processo de tomada de decisões, elas representam somente um estágio inicial para criar uma superfície de custo adequada à definição de projetos geométricos rodoviários.

\section{Diferenças entre as Metodologias Ambientais}

A intersecção entre os TMCs ambientais foi baixa. Os trajetos se sobrepuseram apenas $0,42 \mathrm{~km} 2(6 \%)$, nas cartas de fragilidade e vulnerabilidade, que apresentou uma intersecção maior com o eixo construído $(21,2 \%)$.

Entende-se que o resultado melhor se deve, basicamente, pela forma como as metodologias ponderam a questão do modelado e da estrutura geológica dos terrenos. Enquanto a proposta de Ross (1994) define que os terrenos mais planos possuem os menores custos de deslocamento, pois são menos frágeis, a de Crepani et al. (2001) estabelece que os menores custos (menor vulnerabilidade) correspondem às áreas formadas por colinas e morrotes, de média a baixa declividade e solos com profundidade moderada. Portan-

a 
to, no trajeto efetuado sobre o mapa de fragilidade ambiental, o percurso ocorre nos terrenos com menores declividades, se estabelecendo próximo às várzeas dos rios. Em contrapartida, no trajeto executado sobre o mapa de vulnerabilidade à erosão, estas planícies de inundação são evitadas.

Esta diferença básica entre as propostas pode ser visivelmente observada no trecho localizado nos limites dos municípios de Ribeirão Pires e Suzano, em direção ao norte, na área de várzea do Rio Guaió, até a divisa dos municípios de Suzano e Poá, como ilustra a figura 7.

Figura 7 - Detalhe da comparação dos traçados do rodoanel: oficial e de menores custos

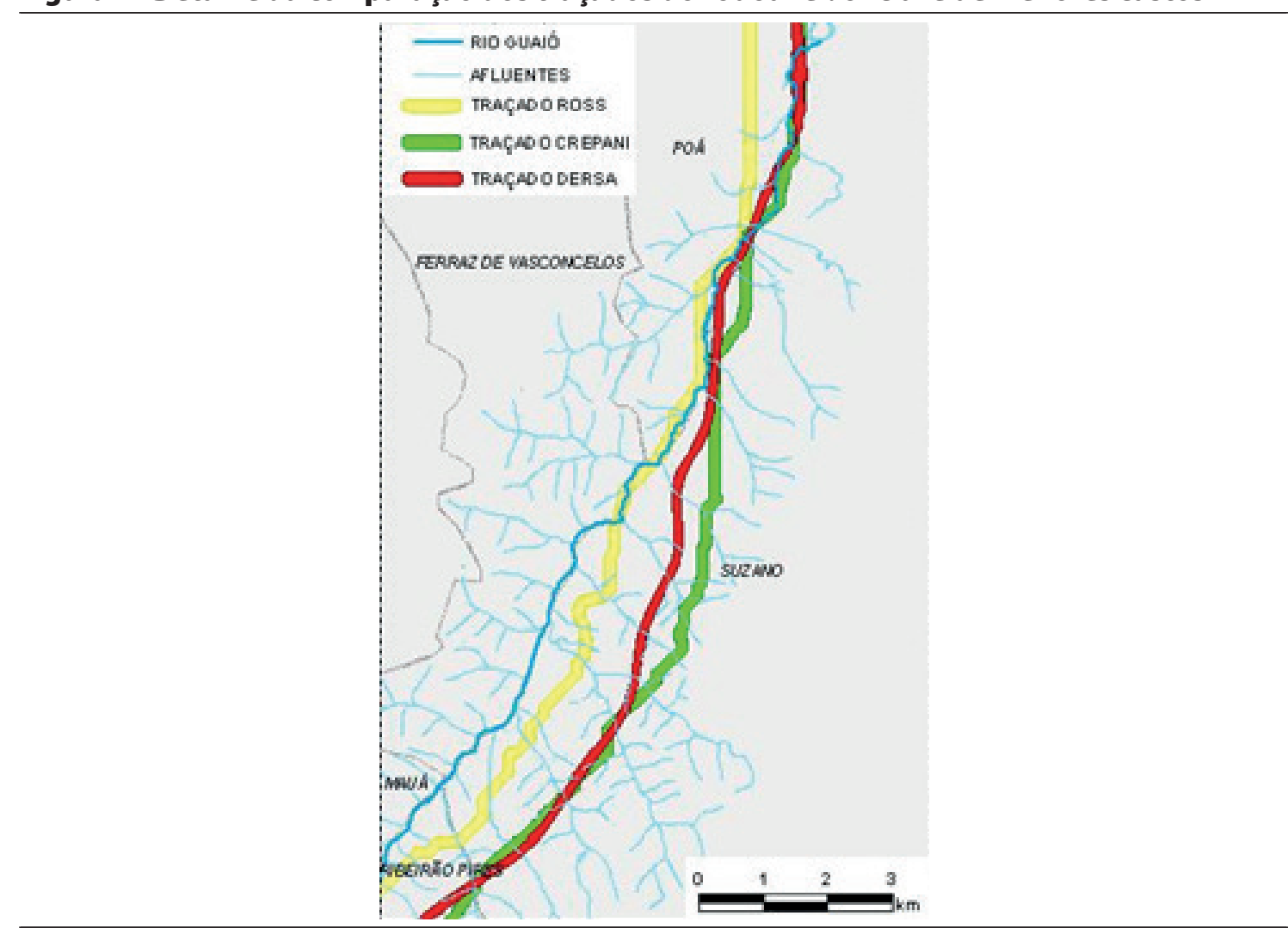

É nesta área que se verificam as maiores distâncias entre os dois traçados, e também onde o trajeto desenvolvido sobre o mapa de vulnerabilidade obtêm as maiores coincidências com o trajeto oficial do Rodoanel. 


\section{CONSIDERAÇÕES FINAIS}

O trabalho analisou o trajeto de menor custo (TMC) ambiental no trecho leste do Rodoanel Metropolitano de São Paulo. O algoritmo de TMC foi aplicado às superfícies de custo de fragilidade ambiental (ROSS, 1994) e vulnerabilidade à erosão (CREPANI, et al., 2001) e os traçados foram comparados ao trajeto construído da rodovia. Constatou-se que a intersecção entre os TMC e o trajeto construído foi baixa: 21,2\% sobre a carta de vulnerabilidade e $4,3 \%$ sobre a carta de fragilidade. Os TMCs também mostraram uma sobreposição pouco relevante entre eles (6\%).

Assim, considera-se que as variáveis ambientais deste estudo de caso se mostraram importantes para a etapa inicial do projeto do empreendimento rodoviário. $\mathrm{O}$ aumento da intersecção entre os TMCs e o traçado construído pode ocorrer com o refinamento das superfícies de custo ambiental, com a incorporação de dados sobre a geometria do traçado, métodos e custos construtivos, procedimentos e custos operacionais.

\section{REFERÊNCIAS BIBLIOGRÁFICAS}

1. ADRIAENSEN, F.; CHARDON, J. P.; DE BLUST, G.; SWINNEN, E.; VILLALBA, S.; GULINCK, H.; MATTHYSEN, E. The application of 'least-cost' modelling as a functional landscape model. Landscape and Urban Planning 64 (2003) 233-247.

2. BAGLI, S.; GENELETTI, D.; ORSI, F. Routeing of power lines through least-cost path analysis and multicriteria evaluation to minimise environmental impacts. Environmental Impact Assessment Review 31 (2011) 234-239.

3. CREPANI, E.; MEDEIROS, J. S.; HERNANDEZ FILHO, P.; FLORENZANO, T. G.; DUARTE, V.; BARBOSA, C. C. F. Sensoriamento remoto e geoprocessamento aplicados ao zoneamento ecológico-econômico e ao ordenamento territorial. São José dos Campos: INPE, 2001.

4. DERSA - DESENVOLVIMENTO RODOVIÁRIO S.A. \& CONSÓRCIO JGP - PRIME. Trecho Leste do Rodoanel Mário Covas: estudo de impacto ambiental - EIA. São Paulo: 2008, Relatório técnico.

5. FELDMAN, S. C.; PELLETIER, R. E.; WALSER, E.; SMOOT, J. C.; AHL, D. (1996). GIS, remote sensing analysis used to select potential route. Pipe Line and Gas Industry, 1996. p. 52-55.

6. IBGE, Mapa de Vegetação do Brasil. Fundação Instituto Brasileiro de Geografia e Estatística: Rio de Janeiro, 2005.

7. LEE, J. STUCKY, D. On applying viewshed analysis for determining least-cost paths on Digital Elevation Models. International Journal of Geographic Information Science. 1998. 12(8) p.891-905. 
8. NOVALINE JAGA, R. M.; SUNDARAM, A.; NATARAJAN, T. Wasteland development using geographic information. International Journal of Remote Sensing. v. 14 (17), 1993. p.32493257. DOI:10.1080/01431169308904439

9. KAWAKUBO, F. S. Representações gráficas do relevo e álgebra de mapas: aplicações no estudo da fragilidade ambiental. Dissertação (Mestrado em Geografia Física). São Paulo: FFLCH-USP, 2005.

10. OLIVEIRA, J. B. Solos do Estado de São Paulo: descrição das classes registradas no mapa pedológico. Campinas: Instituto Agronômico de Campinas - IAC, 1999. Boletim Científico.

11. ROSS, J. L. S. Análise empírica da fragilidade dos ambientes naturais e antropizados. Revista do Departamento de Geografia 8 (1994) 63-74. DOI 10.7154/RDG.1994.0008.0006.

12. ROSS, J. L. S O Registro cartográfico dos fatos geomórficos e a questão da taxonomia do relevo. Revista do Departamento de Geografia 6 (1992) 17-29. DOI 10.7154/RDG.1992.0006.0002.

13. SPÖRL, C. Análise da fragilidade ambiental relevo-solo com aplicação de três modelos alternativos nas bacias do Rio Jaguari-Mirim, Ribeirão do Quartel e Ribeirão da Prata. Dissertação (Mestrado em Geografia Física). São Paulo: FFLCH-USP, 2001.

14. TARIFA, J. R. \& AZEVEDO, T. R. (orgs.) Os climas na cidade de São Paulo: teoria e prática. São Paulo: Laboratório de Climatologia e Biogeografia - Departamento de Geografia - FFLCH-USP, 2001.

15. TRICART, J. Ecodinâmica. Rio de Janeiro: FIBGE / SUPREN, 1977.

16. YU, C.; LEE, J.; MUNRO-STASIUK, M. J. Extensions of least-cost path algorithms for roadway planning. International Journal of Geographical Information Science. 2003. 17(4) p.361-376. 